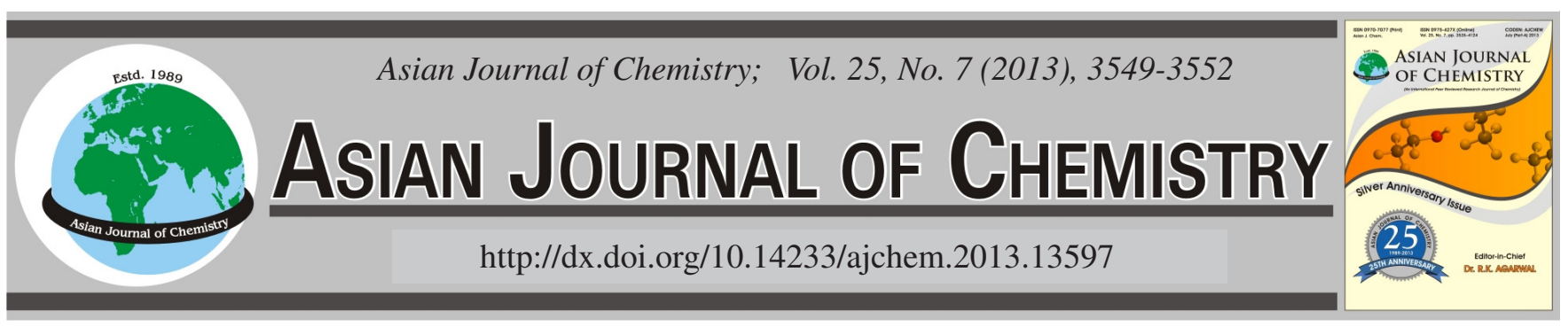

\title{
Effects of Liquid-to-Solid Ratio and Reaction Time on Ammonia- Sulfuric Acid Pretreatment of Achnatherum splendens
}

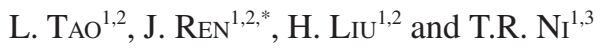

${ }^{1}$ School of Environmental and Municipal Engineering, Institute of Environmental Ecology, Lanzhou Jiaotong University, Lanzhou 730070, P.R. China

${ }^{2}$ Demonstration Center for Experimental Teaching of Environmental Science and Technology in Colleges of Gansu Province, Lanzhou 730070, P.R. China

${ }^{3}$ School of Environmental Science and Engineering, Nankai University, Tianjin 300100, P.R. China
\end{abstract}

*Corresponding author: Fax: +86 931 4856017; Tel: +86 931 4938177; E-mail: renjun@ mail.lzjtu.cn

(Received: 15 February 2012;

Accepted: 4 January 2013)

AJC-12646

\begin{abstract}
For ammonia-sulfuric acid pretreatment of Achnatherum splendens, the ground biomass was first pretreated by soaking in aqueous ammonia with $10 \mathrm{wt} \%$ of ammonia at $55^{\circ} \mathrm{C}$ with $12: 1$ of liquid-to-solid ratio (based on wt) for $36 \mathrm{~h}$. Then the pretreated solids were further treated with $0.5-2 \%(\mathrm{w} / \mathrm{v})$ sulfuric acid at liquid-to-solid ratio of 8:1-15:1 (v/w) for 0.5-3 h at $100{ }^{\circ} \mathrm{C}$. Increasing sulfuric acid concentration and reaction time in the second stage had significant effect on hemicellulose solubilization. Increases in sulfuric acid concentration and reaction time in the second stage caused significant decrease in hemicellulose and significant increase in cellulose and lignin. However, liquid-to-solid ratio had no significant effects on hemicellulose solubilization in the second stage. Liquid-to-solid ratio had also no significant effects on the yield of hemicellulose, cellulose and lignin in the solids after sulfuric acid pretreatment in the second stage. The optimum treatment conditions of the ammonia-sulfuric acid pretreatment were: $10 \mathrm{wt} \%$ of ammonia, $55^{\circ} \mathrm{C}, 36 \mathrm{~h}$ of reaction time, 12:1 of liquid-to-solid ratio (based on wt) in the first stage; $1.5 \%(\mathrm{w} / \mathrm{v})$ sulfuric acid, 8:1 (v/w) of liquid-to-solid ratio, $2 \mathrm{~h}$ of reaction time and $100{ }^{\circ} \mathrm{C}$ in the second stage. Under these conditions, $91.19 \%$ hemicellulose was solubilized and the content of cellulose was increased to $75.49 \%$.

Key Words: Ammonia-sulfuric acid pretreatment, Hemicellulose solubilization, Cellulose, Hemicellulose.
\end{abstract}

\section{INTRODUCTION}

Lignocellulosic materials are attractive feedstock for fuel ethanol production because they are abundant, cheap and renewable, but the low enzymatic accessibility of the native cellulose is a key problem for biomass-to-ethanol. Several processes have been developed for pretreatment of lignocellulosic biomass to improve the enzymatic digestibility, including steam explosion ${ }^{1}$, acid pretreatment ${ }^{2-5}$, alkali pretreatment ${ }^{6,7}$ and wet oxidation ${ }^{8,9}$. Agricultural residues such as wheat straw $^{10,11}$, corn stover ${ }^{12-16}$, bagasse ${ }^{17}$, rice straw ${ }^{18,19}$ and hulls ${ }^{20}$, cotton stalks ${ }^{7}$ and barley ${ }^{21}$ were used in the research on pretreatment of lignocellulosic materials for ethanol production. Less research was focused on the dilute acid pretreatment of grasses and herbs ${ }^{22-24}$ and little research is available on the pretreatment of Achnatherum splendens. Dilute sulfuric acid pretreatment of lignocellulosic biomass is one of the most effective pretreatment methods which predominantly affect hemicellulose with little impact on lignin degradation while soaking in aqueous ammonia can effectively remove lignin from lignocellulosic materials. Therefore, in this study, Achnatherum splendens was first treated by soaking in aqueous ammonia to remove lignin and further treated by sulfuric acid pretreatment to remove hemicellulose.

Achnatherum splendens, which distributes widely in the north of China, is a tufty, perennial herbaceous plant of about $0.5-2.5 \mathrm{~m}$ in height. The plant grows rapidly and has a high tolerance for salt and drought. It is often found growing on infertile and poor land. Of special importance is the fact that the plant could be used for treatment of saline and alkali land and polluted soil. This study was focused on evaluation of the ammonia-sulfuric acid pretreatment of Achnatherum splendens. The effects of reaction parameters on the composition were investigated. The reaction parameters of interest were sulfuric acid concentration, liquid-to-solid ratio and reaction time.

\section{EXPERIMENTAL}

Achnatherum splendens used in the study was obtained from Zhangye city in Gansu province in northwestern China. It was ground and screened to a nominal size of 20-60 mesh 
TABEL-1

EFFECT OF SULFURIC ACID CONCENTRATION ON THE COMPOSITIONS IN AMMONIA SULFURIC ACID TREATED Achnatherum splendens

\begin{tabular}{|c|c|c|c|c|}
\hline Sulfuric acid concentration $(\%)$ & Hemicellulose (\%) & Hemicellulose solubilization (\%) & Cellulose $(\%)$ & Lignin $(\%)$ \\
\hline 0.5 & $9.23 \pm 0.14 a$ & $82.98 \pm 0.26 a$ & $72.55 \pm 0.4 a$ & $14.31 \pm 0.43 a$ \\
\hline 1.0 & $7.47 \pm 0.25 b$ & $86.63 \pm 0.44 b$ & $74.60 \pm 0.32 b$ & $14.64 \pm 0.25 a$ \\
\hline 1.5 & $4.62 \pm 0.11 c$ & $91.93 \pm 0.20 c$ & $76.32 \pm 0.19 c$ & $15.51 \pm 0.13 b$ \\
\hline 2.0 & $4.53 \pm 0.20 c$ & $92.29 \pm 0.33 c$ & $76.36 \pm 0.38 \mathrm{c}$ & $15.77 \pm 0.19 b$ \\
\hline F-value & $472.75 * * *$ & $575.95 * * *$ & $90.10 * * *$ & $19.49 * * *$ \\
\hline
\end{tabular}

Values are means of triplicate measurements \pm standard deviation. Values with the same letters are not significantly different among treatments at $p$ $<0.05$ according to Turkey HSD test

and then dried in oven at $105^{\circ} \mathrm{C}$ for $6 \mathrm{~h}$. The oven-dried samples were stored in valve bags at room temperature until use for pretreatment. Cellulose, hemicellulose and lignin were determined by the methods described by Goering and Vansoest ${ }^{25}$. The initial composition of the Achnatherum splendens was determined to be $45.31 \%$ cellulose, $31.46 \%$ hemicellulose, $9.59 \%$ lignin, $6.45 \%$ moisture content, $1.96 \%$ ash. Each sample was analyzed in duplicate. Statistical analysis was determined by ANOVA in STATISTICA.

Pretreatment process: The two-stage pretreatment was carried out in a $1000 \mathrm{~mL}$ glass flask immersed in a water bath. First, the ground biomass was treated by soaking in aqueous ammonia under the optimum treatment conditions we found in our pre-experiment using a single-factor test (10 wt \% of ammonia, $55^{\circ} \mathrm{C}, 36 \mathrm{~h}, 12: 1$ of liquid-to-solid ratio). After soaking, the solids were washed with deionized water until neutrality and dried in oven at $105^{\circ} \mathrm{C}$ for $6 \mathrm{~h}$. Then the soaking in aqueous ammonia-treated solids were further treated with $0.5-2 \%(\mathrm{w} / \mathrm{v})$ sulfuric acid at liquid-to-solid ratio of 8:1-15:1 (v/w) for $0.5-3 \mathrm{~h}$ at $100{ }^{\circ} \mathrm{C}$. After sulfuric acid pretreatment, the solids were separated by filtering, washed with deionized water until neutrality and dried in oven at $105^{\circ} \mathrm{C}$ for $6 \mathrm{~h}$. The oven-dried samples were stored in valve bags at room temperature for further analysis.

\section{RESULTS AND DISCUSSION}

Effect of sulfuric acid concentration: The washed and dried soaking in aqueous ammonia-treated solids were treated further with sulfuric acid with different concentrations. In the second stage, the treatment conditions were $0.5-2 \%(\mathrm{w} / \mathrm{v})$ sulfuric acid, 15:1 (v/w) of liquid-to-solid ratio, $3 \mathrm{~h}$ of reaction time and $100{ }^{\circ} \mathrm{C}$. The major compositional changes were in hemicellulose. The yield of hemicellulose in the solids after sulfuric acid pretreatment in the second stage decreased from 9.23 to $4.53 \%$ when sulfuric acid concentration was increased from 0.5 to $2 \%$ and cellulose and lignin increased from $72.55 \%, 14.31 \%$ to $76.36 \%, 15.77 \%$, respectively. Changes in sulfuric acid concentration caused significant decrease in hemicellulose $(p<0.001)$ and significant increase in cellulose and lignin $(p<0.001)$. Increasing sulfuric acid concentration had significant effect on hemicellulose solubilization $(p<$ $0.001)$. When sulfuric acid concentration in the second stage was increased from 0.5 to $2 \%$, the hemicellulose solubilization increased from 82.98 to $92.29 \%$. Treatment with $0.5 \%$ sulfuric acid in the second stage achieved $82.98 \%$ of hemicellulose solubilization which was much higher than that $31.82 \%$ we found in our pre-experiment) of pretreatment with $0.5 \%$ sulfuric acid only. The reason is that hemicellulose was partially removed in the first stage by soaking in aqueous ammonia and the hemicellulose content of the pretreated solids decreased to $23.63 \%$. Then the pretreated solid was treated with $0.5 \%$ sulfuric acid which further increased the hemicellulose solubilization to $82.98 \%$. The maximum hemicellulose solubilization was $92.29 \%$ achieved at $2 \%$ sulfuric acid in the second stage. It indicated that the two-stage pretreatment could solubilize hemicellulose effectively (Table-1).

Compared with the treatment of $1.5 \%$ sulfuric acid, the hemicellulose content of pretreated solids increased significantly and the cellulose and lignin contents decreased significantly at the treatments of $0.5 \%$ and $1 \%$ sulfuric acid. For the hemicellulose, cellulose and lignin contents of pretreated solids, there was no significant difference between the treatments of $1.5 \%$ and $2 \%$ sulfuric acid (Table-1).

The hemicellulose solubilization decreased significantly at the treatments of $0.5 \%$ and $1 \%$ sulfuric acid compared with the treatment of $1.5 \%$ sulfuric acid. However, there was no significant difference between the treatments of $1.5 \%$ and $2 \%$ sulfuric acid for the hemicellulose solubilization (Table- 1 ). Treatment with $1.5 \%$ sulfuric acid in the second stage achieved $91.93 \%$ of hemicellulose solubilization which was insignificantly different from the maximum hemicellulose solubilization of $92.29 \%$ achieved in the treatment with a higher sulfuric acid concentration of $2 \%$ (Table-1). It indicated that sulfuric acid concentration had no significant effect on hemicellulose solubilization when higher than $1.5 \%$ in the second stage.

Effect of liquid-to-solid ratio: The washed and dried soaking in aqueous ammonia-treated solids were treated further with sulfuric acid with different liquid-to-solid ratios. In the second stage, the treatment conditions were 8:1-15:1 (v/w) of liquid-to-solid ratio, $1 \%(\mathrm{w} / \mathrm{v})$ sulfuric acid, $3 \mathrm{~h}$ of reaction time and $100{ }^{\circ} \mathrm{C}$. It was found that liquid-to-solid ratio had no significant effects on yield of hemicellulose $(\mathrm{p}>$ $0.05)$, cellulose $(p>0.05)$ and lignin $(p>0.05)$ in the solids after sulfuric acid pretreatment in the second stage. The hemicellulose content of the sulfuric acid pretreated solids in the second stage stayed relatively constant at 7.4-7.6\% and the cellulose content stayed relatively constant at 74.5-74.7 \% and the lignin content stayed relatively constant at 14.1-14.6\%. Liquid-to-solid ratio had no significant effects on hemicellulose solubilization in the sulfuric acid pretreatment in the second stage $(p>0.05)$. The hemicellulose solubilization stayed relatively constant at $86.4-86.7 \%$. The effects of liquidto-solid ratio on the hemicellulose, cellulose and lignin 


\begin{tabular}{|c|c|c|c|c|}
\hline \multicolumn{5}{|c|}{$\begin{array}{c}\text { TABLE-2 } \\
\text { EFFECT OF LIQUID-TO-SOLID RATIO ON THE COMPOSITIONS IN AMMONIA- } \\
\text { SULFURIC ACID TREATED Achnatherum splendens }\end{array}$} \\
\hline Liquid-to-solid (v/w) & Hemicellulose (\%) & Hemicellulose solubilization (\%) & Cellulose $(\%)$ & Lignin $(\%)$ \\
\hline $8: 1$ & $7.58 \pm 0.68 \mathrm{a}$ & $86.40 \pm 1.36 \mathrm{a}$ & $74.48 \pm 0.40 \mathrm{a}$ & $14.12 \pm 0.47 \mathrm{a}$ \\
\hline $10: 1$ & $7.48 \pm 0.30 \mathrm{a}$ & $86.63 \pm 0.53 a$ & $74.52 \pm 0.21 \mathrm{a}$ & $14.21 \pm 0.09 \mathrm{a}$ \\
\hline $12: 1$ & $7.44 \pm 0.55 \mathrm{a}$ & $86.67 \pm 1.17 \mathrm{a}$ & $74.61 \pm 0.37 \mathrm{ab}$ & $14.61 \pm 0.6 b$ \\
\hline $15: 1$ & $7.43 \pm 0.35 \mathrm{a}$ & $86.67 \pm 0.63 a$ & $74.68 \pm 0.20 b$ & $14.63 \pm 0.16 b$ \\
\hline F-value & 1.25 & 1.15 & 0.47 & 3.28 \\
\hline \multicolumn{5}{|c|}{$\begin{array}{l}\text { Values are means of triplicate measurements } \pm \text { standard deviation. Values with the same letters are not significantly different among treatments at } \\
<0.05 \text { according to Turkey HSD test }\end{array}$} \\
\hline \multicolumn{5}{|c|}{$\begin{array}{c}\text { TABLE -3 } \\
\text { EFFECT OF REACTION TIME ON THE COMPOSITIONS IN AMMONIA-SULFURIC ACID TREATED Achnatherum splendens }\end{array}$} \\
\hline Time $(\mathrm{h})$ & Hemicellulose (\%) & Hemicellulose solubilization (\%) & Cellulose $(\%)$ & Lignin $(\%)$ \\
\hline 0.5 & $9.43 \pm 0.11 \mathrm{a}$ & $82.01 \pm 0.20 \mathrm{a}$ & $71.42 \pm 0.47 \mathrm{a}$ & $13.96 \pm 0.45 a$ \\
\hline 1.0 & $6.05 \pm 0.17 b$ & $88.82 \pm 0.31 b$ & $73.63 \pm 0.42 b$ & $14.39 \pm 0.36 b$ \\
\hline 1.5 & $6.02 \pm 0.10 \mathrm{~b}$ & $89.01 \pm 0.18 b$ & $74.21 \pm 0.14 \mathrm{c}$ & $14.45 \pm 0.07 b$ \\
\hline 2.0 & $4.89 \pm 044 c$ & $91.19 \pm 0.35 c$ & $75.49 \pm 0.35 d$ & $14.63 \pm 0.35 b c$ \\
\hline 2.5 & $4.86 \pm 0.47 \mathrm{c}$ & $91.33 \pm 0.26 c$ & $75.58 \pm 0.23 d$ & $14.83 \pm 0.48 \mathrm{~cd}$ \\
\hline 3.0 & $4.83 \pm 0.28 c$ & $91.44 \pm 0.39 c$ & $76.11 \pm 0.17 d$ & $15.09 \pm 0.21 \mathrm{~d}$ \\
\hline F-value & $85.56 * * *$ & $114.23 * * *$ & $19.28 * * *$ & $33.75 *$ \\
\hline
\end{tabular}

contents and the corresponding hemicellulose solubilization were insignificant when liquid-to-solid ratio was increased from $8: 1$ to $15: 1$ in sulfuric acid pretreatment in the second stage (Table-2). However, in our pre-experiment it was found that liquid-to-solid ratio had significant effects on yield of hemicellulose, cellulose and lignin and the corresponding hemicellulose solubilization when liquid-to-solid ratio was increased from 8:1 to 20:1 with $0.5 \%$ sulfuric acid only. It indicated that the liquid-to-solid ratio of $8: 1$ in sulfuric acid pretreatment in the second stage was higher enough for the further pretreatment of the soaking in aqueous ammoniatreated solids in the first stage.

For the hemicellulose content of pretreated solids, there was no significant difference among the treatments of $8: 1$, $10: 1,12: 1$ and $15: 1$ of liquid-to-solid ratio. For the cellulose content of pretreated solids, there was no significant difference among the treatments of 8:1,10:1 and 12:1 of liquid-to-solid ratio. However, there were significant increases in cellulose and lignin at the treatment of 15:1 of liquid-to-solid ratio compared with the treatment of 8:1 of liquid-to-solid ratio. There was no significant difference between the treatments of 8:1 and 10:1 of liquid-to-solid ratio for the content of lignin in pretreated solids (Table-2).

There was no significant difference among the treatments of $8: 1,10: 1,12: 1$ and $15: 1$ of liquid-to-solid ratio for the hemicellulose solubilization. Treatment at $8: 1$ of liquid-to-solid ratio in sulfuric acid pretreatment in the second stage achieved $86.40 \%$ of hemicellulose solubilization which was insignificantly different from the maximum hemicellulose solubilization of $86.67 \%$ achieved in the treatment at a higher liquidto-solid ratio of 15:1 (Table-2). It indicated that the liquid-tosolid ratio had no significant effect on hemicellulose solubilization when higher than $8: 1(\mathrm{v} / \mathrm{w})$ in sulfuric acid pretreatment in the second stage.

Effect of reaction time: The washed and dried soaking in aqueous ammonia-treated solids were treated further with sulfuric acid with different reaction times. In the second stage, the treatment conditions were $0.5-3 \mathrm{~h}$ of reaction time, $1.5 \%$ $(\mathrm{w} / \mathrm{v})$ sulfuric acid, 8:1 of liquid-to-solid ratio, $3 \mathrm{~h}$ of reaction time at $100{ }^{\circ} \mathrm{C}$. The major compositional changes were observed in hemicellulose. Increasing of reaction time resulted in significant decrease in hemicellulose $(p<0.001)$ and significant increase in the cellulose $(p<0.001)$ and lignin $(p<$ 0.05 ). When reaction time was increased from $0.5 \mathrm{~h}$ to $3 \mathrm{~h}$, the hemicellulose content of the sulfuric acid pretreated samples in the second stage ranged from 9.43 to $4.83 \%$, the cellulose content ranged from 71.42 to $76.11 \%$ and the content of lignin ranged from 13.96 to $15.09 \%$. Reaction time had significant effect on hemicellulose solubilization $(p<0.001)$. When reaction time was increased from 0.5 to $3 \mathrm{~h}$, the hemicellulose solubilization increased from 82.01 to $91.44 \%$. Treatment with $1 \mathrm{~h}$ of reaction time in sulfuric acid pretreatment in the second stage achieved $88.82 \%$ of hemicellulose solubilization which was higher than that $(84.50 \%$ we found in our pre-experiment) of pretreatment using sulfuric acid only with $2 \mathrm{~h}$ of reaction time. Treatment with $2 \mathrm{~h}$ of reaction time in sulfuric acid pretreatment in the second stage achieved $91.19 \%$ of hemicellulose solubilization which was comparable to that $(92.57 \%$ we found in our pre-experiment) obtained by the pretreatment using sulfuric acid only with $3 \mathrm{~h}$ of reaction time. It indicated that sulfuric acid pretreatment in the second stage with $2 \mathrm{~h}$ of reaction time could obtain a satisfactory hemicellulose solubilization (Table-3).

Compared with the treatment of $2 \mathrm{~h}$ of reaction time, the hemicellulose content of pretreated solids increased significantly and the cellulose content decreased significantly at the treatments of $0.5,1$ and $1.5 \mathrm{~h}$ of reaction time. There was no significant difference among the treatments of 2, 2.5 and $3 \mathrm{~h}$ of reaction time for the hemicellulose content of pretreated solids. For the contents of cellulose and lignin in pretreated solids there were no significant difference between the treatments of $2 \mathrm{~h}$ and $2.5 \mathrm{~h}$ of reaction time. There was a significant 
increase in lignin at the treatment of $2 \mathrm{~h}$ of reaction time compared with the treatment of $0.5 \mathrm{~h}$ of reaction time for the content of lignin in pretreated solids (Table-3).

Hemicellulose solubilization decreased significantly at the treatments of $0.5,1$ and $1.5 \mathrm{~h}$ of reaction time compared with the treatment of $2 \mathrm{~h}$ of reaction time. There was no significant difference among the treatments of 2, 2.5 and $3 \mathrm{~h}$ for hemicellulose solubilization. Treatment with $2 \mathrm{~h}$ of reaction time in sulfuric acid pretreatment in the second stage achieved $91.19 \%$ of hemicellulose solubilization which was insignificantly different from the maximum hemicellulose solubilization $91.44 \%$ achieved in the treatment with a longer reaction time of $3 \mathrm{~h}$ (Table-3). It indicated that the reaction time had no significant effects on hemicellulose solubilization when over $2 \mathrm{~h}$ in sulfuric acid pretreatment in the second stage.

On the basis of the collective experimental data of hemicellulose solubilization, the optimum operating condition of the sulfuric acid pretreatment in the second stage were found to be: $1.5 \%(\mathrm{w} / \mathrm{v})$ sulfuric acid concentration, $8: 1(\mathrm{v} / \mathrm{w})$ of liquid-to-solid ratio, $2 \mathrm{~h}$ of reaction time and $100^{\circ} \mathrm{C}$ when the first stage pretreatment conditions was fixed to $10 \mathrm{wt} \%$ of ammonia, $55^{\circ} \mathrm{C}, 36 \mathrm{~h}$ of reaction time and $12: 1$ (based on wt) of liquid-to-solid ratio. Under the optimal condition, hemicellulose solubilization was up to $91.19 \%$.

\section{Conclusion}

For ammonia-sulfuric acid pretreatment of Achnatherum splendens, sulfuric acid concentration and reaction time in the second stage had significant effects on hemicellulose solubilization. Both factors also had significant effects on the contents of lignin, hemicellulose and cellulose in the solids after sulfuric acid pretreatment in the second stage. However, liquid-to-solid ratio in the second stage had no significant effects on hemicellulose solubilization. The liquid-to-solid ratio also had no significant effects on the contents of lignin, hemicellulose and cellulose in the solids after sulfuric acid pretreatment in the second stage. The experimental results showed that when the Achnatherum splendens was pretreated by $10 \mathrm{wt} \%$ of ammonia with 12:1(based on wt) of liquid-to-solid ratio at $55{ }^{\circ} \mathrm{C}$ for $36 \mathrm{~h}$ and further treated by $1.5 \%$ sulfuric acid concentration with $8: 1(\mathrm{v} / \mathrm{w})$ of liquid-to-solid ratio at $100{ }^{\circ} \mathrm{C}$ for $2 \mathrm{~h}$, the hemicellulose solubilization reached to $91.19 \%$. The optimum treatment conditions of the ammonia-sulfuric acid pretreatment were: $10 \mathrm{wt} \%$ of ammonia, $55^{\circ} \mathrm{C}, 36 \mathrm{~h}$ of reaction time, $12: 1$ of liquid-to-solid ratio (based on wt) in the first stage; $1.5 \%$ $(\mathrm{w} / \mathrm{v})$ sulfuric acid, 8:1 (v/w) of liquid-to-solid ratio, $2 \mathrm{~h}$ of reaction time and $100{ }^{\circ} \mathrm{C}$ in the second stage. Under these conditions, $91.19 \%$ hemicellulose was solubilized and the content of cellulose was increased to $75.49 \%$. Ammoniasulfuric acid pretreatment could remove hemicellulose effectively. Ammonia pretreatment in the first stage partially removed hemicellulose and swell fibers; compared with the pretreatment using sulfuric acid only, ammonia pre-pretreat- ment reduced sulfuric acid concentration and reaction time and decreased liquid-to-solid ratio in the sulfuric acid pretreatment in the second stage. In addition, this study could serve as a step towards the optimization of pretreatment of Achnatherum splendens. Enzymatic hydrolysis using optimized pretreatment factors and ethanol fermentation need to be studied for bioethanol production since they could not be addressed in this study.

\section{ACKNOWLEDGEMENTS}

This research was supported by Program for Changjiang Scholars and Innovative Research Team in University (IRT0966) and by the National Natural Science Foundation (No. 30970490).

\section{REFERENCES}

1. B. Palmarola-Adrados, M. Galbe and G. Zacchi, J. Chem. Technol. Biotechnol., 80, 85 (2005).

2. L.S. Yan, H.M. Zhang, J.W. Chen, Z.X. Lin, Q. Jin, H.H. Jia and H. Huang, Bioresour. Technol., 100, 1803 (2009).

3. C. Cara, E. Ruiz, J.M. Oliva, F. Saez and E. Castro, Bioresour. Technol., 99, 1869 (2008).

4. S.S. Silva, Z.R. Matos and W. Carvalho, Biotechnol. Progr., 21, 1449 (2005).

5. Y. Yang, R. Sharma-Shivappa, J.C. Bums and J.J. Cheng, Energy Fuels, 23, 3759 (2009).

6. R. Jun, T. Ling, N. Tianri, H. Jianxiu and G. Yamei, Asian J. Chem., 23, 4407 (2011).

7. R.A. Silverstein, Y. Chen, R.R. Sharma-Shivappa, M.D. Boyette and J.A. Osborne, Bioresour. Technol., 98, 3000 (2007).

8. C. Martín, H.B. Klinke and A.B. Thomsen, Enzyme Microb. Technol., 40, 426 (2007).

9. C. Martin and A.B. Thomsen, J. Chem. Technol. Biotechnol., 82, 174 (2007).

10. B.C. Saha, L.B. Iten, M.A. Cotta and Y.V. Wu, Process Biochem., 40, 3693 (2005).

11. S.D. Zhu, Y.X. Wu and Z.N. Yu, Process Biochem., 41, 869 (2006).

12. M. Chen, J. Zhao and L.M. Xia, Biomass Bioenergy, 33, 1381 (2009).

13. T.H. Kim, F. Taylor and K.B. Hicks, Bioresour. Technol., 99, 5694 (2008).

14. T.H. Kim and Y.Y. Lee, Bioresour. Technol., 97, 224 (2006).

15. T.H. Kim and Y.Y. Lee, Appl. Biochem. Biotechnol., 136-140, 81 (2007).

16. S. Kim and M.T. Holtzapple, Bioresour. Technol., 96, 1944 (2005).

17. B.P. Lavarack, G.J. Grifin and D. Rodman, Biomass Bioenergy, 23, 367 (2002).

18. I.C. Roberto, S.I. Mussatto and C.L.B. Rodrigues, Ind. Crops Prod., 17, 171 (2003).

19. K. Karimi, S. Kheradmandinia and M.J. Taherzadeh, Biomass Bioenergy, 30, 247 (2006).

20. B.C. Saha and M.A. Cotta, Biomass Bioenergy, 32, 971 (2008).

21. T.H. Kim and Y.Y. Lee, Appl. Biochem. Biotechnol., 121-124, 1119 (2005).

22. Y. Sun and J.J. Cheng, Bioresour. Technol., 96, 1599 (2005).

23. B.S. Dien, H.J.G. Jung, K.P. Vogel, M.D. Casler, J.F.S. Lamb, L. Iten, R.B. Mitchell and G. Sarath, Biomass Bioenergy, 30, 880 (2006).

24. G.L. Guo, W.H. Chen, W.H. Chen, L.C. Men and W.S. Hwang, Bioresour. Technol., 99, 6046 (2008).

25. H.K. Goering and P.J. Vansoest, Forage Fiber Analysis, Agriculture Handbook, Agricultural Research Services, United States Department of Agriculture, No. 379. 